Disponível em www.scielo.br/paideia

\title{
Atuação de professores do ensino itinerante face à inclusão de crianças com baixa visão na educação infantil
}

\author{
Maria Júlia Canazza Dall'Acqua \\ Universidade Estadual Paulista, Araraquara, Brasil
}

\begin{abstract}
Resumo: No momento em que se discute a inclusão de alunos com necessidades educacionais especiais em escolas regulares, faz-se necessário desenvolver trabalhos de pesquisa que se dediquem a analisar as implicações da formação continuada de professores. Neste sentido, estabeleceu-se o objetivo de investigar aspectos relativos às necessidades de duas professoras itinerantes, participantes de um programa de formação. Tal programa, voltado para o acompanhamento de alunos com baixa visão, pretendeu oferecer a essas professoras, sem conhecimentos específicos em deficiência visual, elementos dessa formação, e analisar a natureza das implicações evidenciadas ao longo do processo, do qual foi possível depreender que o desenvolvimento das funções visuais constitui-se em valioso referencial teórico, bem como o fato de estar regularmente na escola, conversar com as professoras, discutir como proceder, avaliar retroativamente os exercícios e ajudar a planejar estratégias com base nas análises feitas foram as principais vantagens de atuar de forma colaborativa.
\end{abstract}

Palavras-chave: Educação especial. Formação continuada. Deficiência visual. Inclusão. Educação infantil.

\section{Teacher's performance of itinerant teaching in relation to the inclusion of low vision children in elementary education}

\begin{abstract}
At a time in which the inclusion of students with special education needs in regular schools has been discussed, it is necessary to develop researches to evaluate the implications of teachers' continued education. In this sense, the objective of investigating aspects related to the needs of two itinerant teachers was established. Theses teachers are participants of a formation program. Such program has the goal to follow-up low vision students. It managed to offer these teachers, who had no specific knowledge in visual disability, elements of this formation, and also to evaluate the nature of evidenced implications along the process from which it was possible to conclude that the visual functions development is constituted by valuable theorical referential, as well as the fact of being regulary at school, talk to the teachers, discuss how to proceed, evaluate the exercises retroactively and help them to plan strategies based on the analysis done. These were the main advantages of acting in a colaborative manner.
\end{abstract}

Keywords: Special education. Continued formation. Visual disability. Inclusion. Elementary education.

\section{Actuación de profesores del encino itinerante frente a la inclusión de niños con baja visión en la educación infantil}

\begin{abstract}
Resumen: En el momento en que se discute la inclusión de alumnos con necesidades educacionales especiales en escuelas regulares, se hace necesario desarrollar trabajos de investigación que se dediquen a analizar las implicaciones de la formación continua de profesores. En este sentido, se estableció el objetivo de investigar aspectos relativos a las necesidades de dos profesoras itinerantes, participantes de un programa de formación. Tal programa, dirigido hacia el seguimiento de alumnos con baja visión, pretendió ofrecer a esas profesoras, sin conocimientos específicos en deficiencia visual, elementos de esa formación y analizar la naturaleza de las implicaciones evidenciadas a lo largo del proceso, por lo cual fue posible deducir que el desarrollo de las funciones visuales se constituye en valioso referencial teórico, tal como el hecho de estar regularmente en la escuela, hablar con las profesoras, discutir como proceder, evaluar retroactivamente los ejercicios y ayudar a planear estrategias basadas en los análisis hechos, fueron las principales ventajas de actuar de manera cooperativa.
\end{abstract}

Palabras clave: Educación especial. Formación continúa. Deficiencia visual. Inclusión. Educación infantil. 
Cada vez mais firma-se a noção e a necessidade de que sejam incorporados, junto às ações de formação continuada de professores, estejam eles atuando no ensino especial ou não, conteúdos para a aquisição de conhecimentos, competências e atitudes que favoreçam a compreensão das complexas situações de ensino, enfatizando especialmente atitudes de aceitação e respeito às diferenças individuais.

\section{A formação de professores é a}

[...] área de conhecimentos, investigação e de propostas teóricas e práticas que, no âmbito da didática e da organização escolar, estuda os processos por meio dos quais os professores, em formação ou em exercício, individualmente ou em equipe, em experiências de aprendizagem por meio das quais adquirem ou melhoram os conhecimentos, competências e disposições, e que lhes permite intervir profissionalmente no desenvolvimento do seu ensino, do currículo e da escola, com o objetivo de melhorar a qualidade da educação que os alunos recebem. (Baumel \& Castro, 2002, p. 7).

Num esforço de buscar um ensino de qualidade para todos os alunos, os conhecimentos necessários à formação de professores, inclusive dos especializados, que são aqueles que atuam na educação especial, ou na educação especial que auxilia a educação comum a realizar a inclusão, necessitam estar assentados sobre todo o conhecimento científico desenvolvido a respeito de quais são as competências exigidas por essa área, no atual momento sócio-político em que se discute a educação inclusiva.

A sociedade moderna é altamente complexa, bem como a realidade do sistema educacional brasileiro e, para atender parte dessa complexidade, no que diz respeito às necessidades educacionais especiais, é preciso garantir a oferta de diferentes tipos de apoio a essas necessidades. E, como bem lembra Mendes (2002, p. 13),

[...] se as necessidades educacionais especiais não desaparecem com a mera inserção dos alunos na classe comum, e se os professores do ensino regular muito provavelmente não conseguirão atender as necessidades de alguns de seus alunos, seria necessário prover apoios de professores especializados a fim de que se possa garantir uma educação devida. A função do professor especi- alizado seria a de apoiar o processo educacional dos alunos com necessidades educacionais especiais, preferencialmente em classes comuns ou, em caráter extraordinário, atuando em serviços de educação especial.

À medida que a orientação de natureza inclusiva segue, torna-se cada vez mais necessário e complexo o processo de formação de professores da educação especial, seja na busca da definição de seus papéis no cenário educacional que se apresenta, seja no que diz respeito aos conhecimentos necessários para a consolidação de práticas pedagógicas e de condições de profissionalidade para o enfrentamento de uma realidade em mudança.

Num contexto de formação de professores predominantemente categorial, a

[...] formação generalista também é dificultada pela própria natureza da produção científica da área, que tem sido categorial e onde se leva anos para formar um professor que seja competente para dominar e acompanhar as inovações educacionais relacionadas a uma única deficiência. Um professor de surdos, por exemplo, apenas para adquirir competência para usar e ensinar língua de sinais leva um longo tempo. É certo que seria mais prático formar um professor generalista para dar conta das necessidades das nossas escolas, mas isso só seria possível se sacrificássemos a qualidade do ensino. Professores com formação insuficiente irão produzir um ensino medíocre. Professores generalistas que atendem qualquer tipo de aluno, provavelmente vão ter um conhecimento mínimo de cada área e ensinarão também o mínimo. (Mendes, 2002, p. 16).

Tais reflexões dizem respeito não só à formação inicial, mas também à continuada. Hoje, a figura do professor da educação especial é central no contexto da educação inclusiva. Ele tem sido chamado a se preparar para enfrentar, e responder às novas demandas que se apresentam no contexto em que atua, num modelo de formação continuada, mesmo quando essa formação trilha caminhos ainda completamente novos, como é o caso da modalidade de atuação denominada "professor do professor". Nesse sentido,

[...] sendo a reflexão considerada um fator fundamental no desenvolvimento profissional e institucional, tão necessários à implementação da orientação inclusiva nas escolas, é possível propor um aprofundamento no papel dos professores da educação especial, enquanto responsáveis por uma 
formação contínua dos professores da escola regular. (Baumel \& Castro, 2002, p. 10).

Assim, quanto à terminologia, estaríamos considerando que esse professor do ensino regular, com um mínimo de conhecimento e prática sobre o alunado especial e diversificado, diferenciar-se-ia do professor categorial, ou especialista nas diferentes necessidades educacionais especiais, "[...] quer seja para atendimento direto à essa população, quer seja para apoio ao trabalho realizado pelos professores de classes regulares que integrem esses alunos." (Glat \& Nogueira, 2002, p. 23).

Como afirma Sassaki (1997), a inclusão é “[...] um processo pelo qual a sociedade se adapta para poder incluir, em seus sistemas sociais gerais, pessoas com necessidades educacionais especiais e, simultaneamente, estas se prepararam para assumir seus papéis na sociedade" (p.41).

Contudo, ressalta que a inclusão não se caracteriza por ser apenas uma permanência em sala de aula, junto com os demais alunos. E, mais importante, que esse conceito não traz em seu bojo a idéia de negação de serviços especializados àqueles que deles necessitem.

Ao contrário, implica numa reorganização do sistema educacional, o que acarreta a revisão de antigas concepções e paradigmas educacionais, na busca de se possibilitar o desenvolvimento cognitivo, cultural e social desses alunos, respeitando suas diferenças e atendendo às suas necessidades (Glat \& Nogueira, 2002, p. 26).

A despeito de uma efetiva tomada de posição em favor da inclusão e das práticas inclusivas, nos documentos e na legislação recente, "[...] não parece haver consenso sobre as implicações pedagógicas e escolares implícitas no princípio da inclusão." (Mendes, 1999, p. 79).

O imperativo moral de enfrentamento da desigualdade social numa sociedade tão desigual quanto a nossa, tem se feito acompanhar por políticas de "educação para todos". Contudo, a premissa, por si só, não referenda políticas de inclusão, até porque nosso sistema educacional não contempla requisitos mínimos para atender a urgência de uma reestruturação que se faz necessária.

$\mathrm{O}$ perfil do professor generalista parece não garantir competência para que ele esteja apto a se responsabilizar pela educação e não apenas pela permanência de alunos com necessidades educacionais especiais nas escolas regulares. A exigência parece ser a de que

[...] o professor do ensino regular adquira formação para fazer frente a uma população que possui características peculiares, por outro exige que o professor de educação especial amplie suas perspectivas, tradicionalmente centradas nessas características. (Bueno, 1999, p. 162).

A provisoriedade da política de formação docente no país contribui para que, em conjunto, com todas as dificuldades que caracterizam o sistema educacional brasileiro, a formação continuada apresente-se como um período importante para o desenvolvimento e a consolidação de novas aprendizagens necessárias às atuais demandas, sejam elas decorrentes do movimento de inclusão, ou oriundas da própria diversidade e complexidade que é a área da educação especial. A formação do professor especializado, dadas as características, necessidades e procedimentos pedagógicos específicos a cada uma das necessidades educacionais especiais, coloca exigências que excedem o período da formação básica inicial.

Considerando que a qualificação docente necessária para a escola que se quer construir para a sociedade moderna tem se tornado cada vez mais complexa, exigindo que o perfil desejado para o professor do ensino regular seja bastante ambicioso, diante da realidade do sistema educacional brasileiro, e que sempre haverá um limite acerca do que o professor comum poderá fazer numa sala de aula para atender as necessidades de todos os seus alunos, mesmo que se melhore ao máximo a formação desse professor, ainda assim, haverá a necessidade de apoio do professor de ensino especial, para atender necessidades educacionais que são mais diferenciadas [...] Há ainda o reconhecimento de que uma educação de qualidade, que se propõe a atender não apenas o mínimo, mas o máximo possível das necessidades desses alunos, dependeria da oferta desses suportes. (Mendes, 2002, p. 12-13).

Refletindo sobre as questões que se tentou abordar até aqui, o presente trabalho de pesquisa foi estabelecido com o objetivo de investigar aspectos relativos às necessidades manifestas por duas professoras itinerantes, participantes de um programa 
de formação continuada. Tal programa, voltado para o acompanhamento de seus alunos com visão subnormal ou baixa visão, pretendeu oferecer a essas professoras, sem formação específica em deficiência visual, elementos da formação categorial, e analisar a natureza das exigências, necessidades e dificuldades evidenciadas ao longo do processo de acompanhamento.

Para conduzir um trabalho de estimulação de desenvolvimento, tendo a visão como núcleo articulador para todas as intervenções, perguntou-se quais, e de que natureza, deveriam ser as estratégias empregadas. A análise feita, com base nas informações obtidas no decorrer do processo. teve por meta subsidiar a definição de princípios norteadores para o estabelecimento de um programa de intervenção.

\section{Método}

\section{Participantes}

Participaram da pesquisa duas professoras e seus alunos.

As professoras, formadas em Pedagogia, com habilitação em Educação Especial: ensino do deficiente mental, obtida há dez anos, integravam o quadro da Rede Municipal de Ensino da cidade de Araraquara/ SP, atuando no ensino especial, e selecionadas por indicação da Senhora Coordenadora Técnica da Educação Especial pelo fato de que, no período, possuíam alunos com visão subnormal, ou baixa visão, matriculados em suas turmas de educação infantil e berçários. Identificadas, por nomes fictícios, respectivamente Maria (36 anos) e Cecília (34 anos), eram integrantes do programa de apoio pedagógico especializado, na modalidade ensino itinerante.

Os alunos participantes, também identificados com nomes fictícios, respectivamente Nino e Saulo, serão caracterizados na tabela 1 , que se segue:

\section{Local}

Os dados foram coletados em duas unidades escolares, denominadas Centros de Educação e
Recreação (CERs) da Rede Municipal de Educação, localizados em bairros não centrais da cidade de Araraquara, interior do estado de São Paulo.

\section{Materiais}

Para coleta de dados foram usados lápis, borracha, caneta, folhas de papel e caderno.

\section{dados}

Procedimentos para coleta e análise dos

Preliminarmente foram realizados contatos com a Secretaria Municipal de Educação com o objetivo de obter aceite para a realização do trabalho e, em seguida, com as professoras itinerantes que estavam atuando com crianças com baixa visão, com o propósito de verificar o interesse das mesmas em participar da pesquisa. Assim que foram definidas as duas professoras participantes, foram realizadas as visitas iniciais às escolas para o estabelecimento dos contatos e do cronograma que levariam ao início da pesquisa em cada um dos CERs. Dado que as duas professoras participantes atuavam no período matutino, definiu-se com as mesmas uma manhã na semana para cada uma das visitas. Com a Profa. Maria ficou combinado que o trabalho seria realizado às quartas-feiras e, com a Profa. Cecília, às quintasfeiras, sendo que tal agendamento foi interrompido apenas em função de imprevistos, seja por parte da pesquisadora, da professora ou do aluno.

Nos dois CERs em que atuavam as professoras itinerantes o trabalho foi realizado segundo orientação similar, começando inicialmente no espaço em que a berçarista estava com Nino e a professora com Saulo, ambas juntamente com as demais crianças, fosse na área livre, na sala de aula ou na sala de multimeios ${ }^{1}$. Lá chegando havia uma diálogo com elas sobre o ocorrido na semana anterior, sendo também uma oportunidade para observar as crianças participantes em contato com seus demais colegas, com os brinquedos e no espaço físico. Após esse início, deslocávamos para uma sala específica, reservada para esse fim, na qual era realizada a avaliação e a estimulação da visão residual de Saulo e Nino, por

Tabela 1. Caracterização das crianças participantes

\begin{tabular}{|l|l|l|l|l|l|}
\hline Identificação & Idade & \multicolumn{1}{|c|}{ Sexo } & \multicolumn{1}{|c|}{$\begin{array}{c}\text { Posição na constelação } \\
\text { familiar }\end{array}$} & $\begin{array}{c}\text { Professora } \\
\text { responsável }\end{array}$ & \multicolumn{1}{|c|}{ Condição visual } \\
\hline Nino & 3 anos & Masculino & $2^{\circ}$ filho & Maria & $\begin{array}{l}\text { Atrofia de nervo óptico } \\
\text { em ambos os olhos }\end{array}$ \\
\hline Saulo & 4 anos & Masculino & $2^{\circ}$ filho & Cecilia & Cegueira cortical \\
\hline
\end{tabular}


aproximadamente 40 minutos, período em que, com a professora itinerante, discutiam-se também os próximos passos do planejamento, com base no desempenho do aluno e nas proposições teóricas de Barraga, Morris, Collins e Hollis, autores tomados referência para nortear a intervenção, dada a solidez da proposta, extensamente usada em diferentes países, mostrando adequação a distintas realidades raciais e culturais, tal como justificado e discutido em Dall'Acqua (2002). Finda essa etapa conjunta, apenas as professoras itinerantes permaneciam nos respectivos CERs. em contato com a berçarista e a professora, para realizar as atividades inerentes ao apoio pedagógico.

A metodologia do estudo foi de natureza qualitativa, e o contato com o universo pesquisado foi prolongado e direto, razão pela qual a escolha metodológica recaiu sobre a pesquisa participante.

Com relação à escolha da abordagem qualitativa, segundo Bogdan e Biklen (1994) este tipo de pesquisa envolve a obtenção de dados descritivos, posto que esta abordagem é, por natureza, descritiva. Estes dados são obtidos no contato do pesquisador com a situação estudada, priorizando mais o processo do que o produto e preocupando-se em relatar a perspectiva dos participantes.

Utilizamos a expressão investigação qualitativa como um termo genérico que agrupa diversas estratégias de investigação que partilham determinadas características. Os dados recolhidos são designados por qualitativos, o que significa ricos em pormenores descritivos relativamente às pessoas, locais e conversas, e de complexo tratamento estatístico. As questões a investigar não se estabelecem mediante a operacionalização de variáveis sendo, outrossim, formuladas com o objetivo de investigar os fenômenos em toda a sua complexidade e em contexto natural [...] Privilegiam, essencialmente, a compreensão dos comportamentos a partir da perspectiva dos sujeitos da investigação [...] Recolhem normalmente os dados em função de um contacto aprofundado com os indivíduos, nos seus contextos ecológicos naturais. (Bogdan \& Biklen, 1994, p. 16).

\footnotetext{
${ }^{1}$ Sala de multimeios: designação utilizada no estabelecimento escolar para se referir à sala em que estão organizados diversos espaços de recreação para serem vivenciados de diferentes formas e com diferentes objetivos. Exemplo: brinquedos, casinha, televisão, vídeo, baú com roupas para apresentações, fantoches.
}

De acordo com os autores citados, a investigação qualitativa utiliza-se da observação participante.

$\mathrm{O}$ investigador introduz-se no mundo das pessoas que pretende estudar, tenta conhecê-las, dar-se a conhecer e ganha sua confiança, elaborando um registro escrito e sistemático de tudo aquilo que ouve e observa. O material assim recolhido é contemplado com outros tipos de dados, como registros escolares, artigos de jornal e fotografias. (Bogdan \& Biklen, 1994, p. 16).

Percebe-se que a abordagem qualitativa utiliza a investigação do campo onde ocorre o fenômeno a ser estudado, para coletar seus dados. Segundo Bogdan e Biklen (1994), em Educação, a investigação qualitativa é freqüentemente designada como naturalista porque o investigador freqüenta os locais em que se verificam naturalmente os fenômenos nos quais se está interessado, incidindo os dados recolhidos nos comportamentos naturais das pessoas como, conversar, visitar, observar, comer.

A coleta de dados estendeu-se durante um ano letivo, período em que foram realizados treze encontros com a professora Maria e quatorze com a professora Cecília. Tal diferença no número de encontros ocorreu, por exemplo, em função de calendário de cada uma das escolas, feriados distribuídos por diferentes dias da semana no decorrer do ano letivo, entre outros motivos.

\section{Resultados}

\section{Professora Maria e seu aluno}

Ao realizar os contatos inicias no CER em que atuava a professora Maria e o aluno Nino, verificouse que não havia um planejamento de atividades. Em conversa, ela relatou que não sabia o que propor, nem como orientar a berçarista. No entanto, mesmo com essa dificuldade de estabelecer objetivos, a professora Maria fazia atendimentos da seguinte forma: colocava objetos diante do rosto de Nino, falando com ele, tentando estimulá-lo, pegava suas mãos, levando-as a tocar no objeto. Assim que isso acontecia, a criança segurava o objeto e o levava à boca, ficando assim com ele, passando a língua por toda sua superfície, sem olhar para o mesmo.

O ambiente em que a situação ocorria era na sala do berçário, junto com as demais crianças, num colchonete posicionado no chão, ao centro da referida sala. Havia todo tipo de interferência, as demais crianças distraiam a atenção tanto da berçarista como 
da professora Maria, por necessitarem de cuidados a todo momento, como é próprio de um trabalho realizado com crianças pequenas, de berçário.

Assim sendo, dado que as condições observadas não estavam garantindo um trabalho efetivo, decidiuse, em conjunto com a Profa. Maria, que tanto o local como as atividades precisariam ser revistas.

A primeira característica evidenciada na avaliação de habilidades visuais do aluno mostrou que o mesmo não usava a visão. Ele substituía essa via sensitiva pela exploração com a boca, pelo tato e pela manipulação de objetos. Assim sendo, em primeiro lugar, decidiu-se estimular a visão por meio do "olhar para" e, para tanto, o atendimento passou a ser realizado em ambiente tranquiilo, sem interferências externas. Uma sala foi preparada especificamente para esse fim. Além da redução na quantidade de estímulos sonoros e visuais, a sala foi também escurecida, para ser possível trabalhar com luzes.

O segundo aspecto destacado que começou a ser discutido com a professora foi a distância, pois esse aspecto não era levado em conta, já que essa condição não era percebida como relevante.

Aliando o "olhar para", usando para tanto objetos interessantes e em ambiente propício para destacar ainda mais as características visuais dos mesmos, com distância adequada e integrando com a manipulação funcional, após um mês de trabalho Nino começou a integrar o sistema viso-motor. Objetos que estavam sendo manipulados começaram a ser explorados visualmente e não mais levados à boca.

Cabe destacar também que Nino usava tampão, por apresentar estrabismo. Esse era um aspecto adicional que começou a ser trabalhado com a professora, para que ela pudesse desenvolver uma maior compreensão sobre o que acontecia e pudesse, também, tomar decisões em relação a como intervir, selecionando materiais, brinquedos e propondo situações mais favoráveis à visualização.

Feitas essas modificações, a própria professora começou a propor intervenções, relatando que observava mudanças positivas e favoráveis no comportamento de Nino. A primeira sugestão de alteração foi passar a usar um cadeirote no qual ele pudesse permanecer sentado, e não mais no chão ou colchonete em que ele ficava deitado, auto manipulando-se, na maior parte do tempo. Feita essa alteração com sucesso, foi possível começar a trabalhar o manuseio de objetos na linha média, constituindo-se esse o novo objetivo almejado e que passou a ser associado ao "olhar para", formando uma integração viso-motora. Teve início também o trabalho de força e uso das mãos, especialmente a esquerda que não respondia, ficando fechada, repousando sobre o colo de Nino. Foi estabelecido como objetivo o desenvolvimento da força muscular das mãos, especialmente a esquerda, por meio do agarrar, puxar e arrancar que, por serem movimentos mais globais, sem a especialização da coordenação motora fina, podiam ser conseguidos primeiramente, visando em seguida os movimentos mais refinados e complexos, trabalhados posteriormente.

Dado que mudanças começaram a ser percebidas no repertório de habilidades do aluno, a professora passou a ficar mais confiante, investindo mais na realização das atividades e na preparação de materiais. Outro aspecto que chamou a atenção foi o fato de que Nino, ficando mais ativo, passou a interagir mais no ambiente e, dessa forma, sua permanência no Berçário 1 começou a ser questionada, de modo que no início do segundo semestre letivo ele foi remanejado para o Berçário 2, para ficar com um grupo de crianças mais compatível com sua idade cronológica.

Após ter sido possível manter o "olhar para", o próximo objetivo passou a ser "localizar", "fixar" e, posteriormente, "seguir" objetos, luzes, pessoas e demais estímulos, em geral, integrando-o com o uso conjunto das duas mãos, na linha média, visando realizar a atividade de maneira integrada, não dissociando coordenação motora e visão.

Atingido esse objetivo, a coordenação visomotora passou a incidir sobre o trabalho integrado das duas mãos, na linha média, porém cada uma das mãos realizando uma atividade diferente como, por exemplo, uma das mãos segurando um pino e a outra levando uma peça grande para ser encaixada no furo central, usando a visão.

\section{Professora Cecília e seu aluno}

Também como professora itinerante, a atuação da professora Cecília envolvia atendimento direto à criança, com orientação à professora nesse CER. Cabe destacar que nessa sala em que estava matriculado, Saulo apresentava uma defasagem idade/série, ficando com crianças mais novas, visto que o critério que regeu essa colocação foi o critério 
de repertório de habilidades, e não o de idade cronológica. Por essa razão, embora contasse com quatro anos de idade, Saulo estava matriculado em um berçário, com crianças de dois anos de idade cronológica. Após o início do trabalho de estimulação ele foi remanejado para uma sala denominada Classe Intermediária (CI), destinada a crianças de três anos, que faziam a transição entre creche e educação infantil, enfocando o desenvolvimento da linguagem e coordenação motora.

Nessa sala de CI não havia atividades sendo realizadas que fossem voltadas para as necessidades de Saulo. Não havia um planejamento que o contemplasse, pois a professora não sabia o que fazer. Ele participava das brincadeiras, brincando sozinho no tanque de areia, e participava também das atividades nas quais ele podia conversar, responder verbalmente, dado que ele tinha uma boa comunicação, quando do início das atividades de pesquisa. Em todas as demais atividades realizadas ele, apenas "assistia" o que os outros faziam.

A professora Cecília, em nosso primeiro encontro, mencinou que sabia dos problemas visuais de Saulo e que, por essa razão, julgava que seria necessário investir na estimulação do tato, como via substitutiva para aprendizagem. De posse do relatório oftalmológico a professora não conseguia interpretar o conteúdo do mesmo e nem traduzí-lo sob a forma de atividades. Acreditava que o aluno era praticamente cego e que, portanto, não tinha nenhuma condição de usar a visão. Nessa tentantiva de estimular o uso das mãos, a professora preparou uma pequena bacia com água e, dentro dela, colocou bolas de gude, que Saulo deveria localizar com os movimentos das mãos na água. Permanecendo nessa procura por um pouco mais de 20 minutos, ao final Saulo havia localizado todas as bolinhas, mas por movimentos aleatórios, que eventualmente levavam sua mão a encontrá-las.

Conversando com a professora Cecília, percebeu-se que para ela a intervenção deveria ser embasada no uso das mãos. Não lhe ocorreu que, se a atividade com a água na bacia fosse realizada, ela o deveria ser com o uso de bolinhas visualmente atrativas, para que Saulo pudesse encontrá-las usando a visão, uma de cada vez, pela discriminação do objeto em contraste com o meio no qual estava.
Após avaliação, o trabalho de intervenção centrou-se no desenvolvimento e aperfeiçoamento da utilização da motricidade visual, em especial realizando convergência, acomodação, seguimento, focalização e coordenação binocular. Para tanto foram estabelecidas atividades, materiais e procedimentos para permitir que a docente fosse realizando um aprofundamento, tanto nos aspectos práticos como também teóricos, para justificar a intervenção e solidificar sua independência em relação à pesquisadora, como é objetivo do ensino colaborativo.

A transferência de atenção foi também estabelecida como meta, na hierarquia das possibilidades, das mais simples rumo às mais complexas. Inicialmente transferência entre dois objetos, passando a três, guardando uma distância máxima de três metros entre Saulo e os objetos de tamanho médio dispostos a sua frente. Contudo, dado que havia prescrição de uso do tampão no olho directo, para estimular o funcionamento do esquerdo, a realização de atividades que exigissem esforço visual levou ao surgimento de um forte nistagmo ${ }^{2}$ de reação no olho melhor, indicando esforço visual na tentativa de estabelecer fixação.

O trabalho da professora seguiu com acompanhamento contínuo e constante, realizando intervenções baseadas em decisões resultantes dos estudos teóricos (Barraga \& Morris, 1985; Barraga, Collins \& Hollis, 1985). O objetivo dessa forma de intervir estava pautado na convicção de que a formação continuada deveria propiciar elementos para que a professora fosse crítica em relação à sua atuação, tomando decisões baseadas na observação de comportamentos da criança e na literatura que contemplava os pressupostos teóricos necessários. Convicta de que a cooperação entre pesquisadora e professora ofereceria as situações mais ricas e proveitosas para o desenvolvimento de habilidades para intervir, o trabalho procurou criar condições favoráveis para consolidar essa parceria.

\section{Considerações Finais}

De maneira geral, as idéias que se têm sobre a natureza e o curso do desenvolvimento da visão são muito limitadas e distorcidas. Há uma crença

\footnotetext{
${ }^{2}$ Nistagmo: movimento rápido e involuntário do globo ocular, que pode ser em um só sentido (horizontal, vertical, rotatório), ou em dois (Ferreira, 1988).
} 
generalizada que a criança adquire visão automaticamente, sem precisar ser ensinada, diferentemente do que ocorre com a aquisição da linguagem. Para compreender tal fato, basta que se observe o comportamento de pais de uma criança pequena: para que aprenda a falar são fornecidos diferentes tipos de modelos, a compreensão e a emissão são sucessivamente incentivadas em diferentes situações e é consenso que, sem a imitação dos pares, a linguagem oral não ocorre espontaneamente. No entanto, muito provavelmente, essa mesma criança não será intencionalmente ensinada a ver e, mesmo assim, ela desenvolverá essa habilidade. "Confirma-se", assim, a impressão de que a visão ocorre espontaneamente, como resultado apenas de um processo de maturação. $\mathrm{O}$ valor do ambiente, da aprendizagem e do treinamento não são levados em consideração. Em se tratando daquelas pessoas que apresentam déficits nas habilidades visuais, o entendimento de que se aprende a ver sem treino tende a se constituir em um aspecto extremamente desfavorável.

Discordando dessa posição, o trabalho de pesquisa desenvolvido baseou-se no pressuposto de que o desenvolvimento das funções ópticas e perceptivas constitui-se em valioso referencial teórico. Assim, o fato de ir até a escola regularmente, conversar com as professoras, discutirmos juntas como proceder, avaliar retroativamente os exercícios e ajudar a planejar algumas estratégias com base nas análises feitas foram as principais vantagens de atuar de forma colaborativa. Num momento em que se discute como viabilizar a inclusão, parece necessário enfatizar que a inclusão necessita ser desenvolvida, apoiada e viabilizada, por meio de políticas claras e condições favoráveis ao enfrentamento dos problemas que estão postos.

\section{Referências}

Barraga, N. C., \& Morris, J. E. (1985) Programa para desenvolver a eficiência no funcionamento visual: Guia para planejamento das lições (J. L. Venturini, Trad.). São Paulo: Fundação para o Livro do Cego no Brasil.

Barraga, N. C., Collins, M. E., \& Hollis, J. (1985) Programa para desenvolver a eficiência no funcionamento visual: Livro de informações sobre visão subnormal (J. L. Venturini, Trad.). São Paulo: Fundação para o Livro do Cego no Brasil.
Baumel, R. C. R., \& Castro, A. M. (2002). Formação de professores e a escola inclusiva : Questões atuais. Integração, 14(24), 6-11.

Bogdan, R. O., \& Biklen, S. K. (1994). Investigação qualitativa em educação: Uma introdução à teoria e aos métodos. Porto: Porto Editora.

Bueno, J. G. S. (1999). A educação inclusiva e as novas exigências para a formação de professores: Algumas considerações. Em M. A. V. Bicudo, \& C. A. da Silva Jr (Orgs.), Formação do educador $e$ avaliação educacional: Formação inicial e contínua (p. 149-164). São Paulo: Editora UNESP.

Dall'Acqua, M. J. C. (2002). Intervenção no ambiente escolar: Estimulação visual de uma criança com visão subnormal ou baixa visão. São Paulo: Editora UNESP.

Ferreira, A.B.O. (1988). Novo Dicionário da Língua Portuguesa. Rio de Janeiro: Nova Fronteira

Glat, R., \& Nogueira, M. L. L. (2002). Políticas educacionais e a formação de professores para a educação inclusiva no Brasil. Integração, 14 (24), 22-27.

Mendes, E. G. (1999). Diretrizes e parâmetros curriculares nacionais e a educação especial: inclusão ou exclusão da diversidade? Em M. A. V. Bicudo, \& C. A. da Silva Jr (Orgs.), Formação do educador: Avaliação institucional, ensino e aprendizagem (pp. 73-90). São Paulo: Editora UNESP.

Mendes, E. G. (2002). Desafios atuais na formação do professor de educação especial. Integração, 14(24), 12-17.

Sassaki, R. K. (1997). Inclusão: Construindo uma sociedade para todos. Rio de Janeiro: WVA.

Endereço para correspondência:

Maria Júlia Canazza Dall'Acqua. Faculdade de Ciências e Letras, Departamento de Psicologia da Educação, Rod. Araraquara-Jaú, km. 1, CEP 14800-901, Araraquara-SP, Brasil. E-mail: juliacandal@gmail.com

Artigo recebido em 19/01/2007. Aceito para publicação em 05/04/2007. 